\title{
IQGAP1 Regulates Adult Neural Progenitors In Vivo and Vascular Endothelial Growth Factor-Triggered Neural Progenitor Migration In Vitro
}

\author{
Laurent Balenci, ${ }^{1,2,3}$ Yasmina Saoudi, ${ }^{2,3,4}$ Didier Grunwald, ${ }^{1,2,3}$ Jean Christophe Deloulme, ${ }^{1,2,3}$ Alexandre Bouron, ${ }^{2,5}$ \\ André Bernards, ${ }^{6}$ and Jacques Baudier ${ }^{1,2,3}$ \\ ${ }^{1}$ Institut National de la Santé et de la Recherche Médicale (INSERM), Unité 873, Laboratoire Transduction du Signal, F-38054 Grenoble, France, \\ ${ }^{2}$ Commissariat à l'Energie Atomique, Institut de Recherche en Technologies et Sciences pour le Vivant, F-38054 Grenoble, France, ${ }^{3}$ Université Joseph \\ Fourier, F-38054 Grenoble, France, ${ }^{4}$ INSERM, Unité 836, Groupe de Physiopathologie du Cytosquelette, F-38054 Grenoble, France, ${ }^{5}$ Centre National de la \\ Recherche Scientifique, Unité Mixte de Recherche 5249, Laboratoire de Chimie et Biologie des Métaux, F-38054 Grenoble, France, and ${ }^{6}$ Massachusetts \\ General Hospital Cancer Center, Charlestown, Massachusetts 02129
}

In the germinative zone of the adult rodent brain, neural progenitors migrate into niches delimited by astrocyte processes and differentiate into neuronal precursors. In the present study, we report a modulating role for the scaffolding protein IQGAP1 in neural progenitor migration. We have identified IQGAP1 as a new marker of amplifying neural progenitor and neuronal precursor cells of the subventricular zone (SVZ) and the rostral migratory stream (RMS) in the adult mouse brain. To determine functions for IQGAP1 in neural progenitors, we compared the properties of neural progenitor cells from wild-type and Iqgap1-null mutant mice in vivo and in vitro. The in vivo studies reveal a delay in the transition of de novo neural progenitors into neuronal precursor cells in Iqgap1-null mice. In vitro, we demonstrated that IQGAP1 acts as a downstream effector in the vascular endothelial growth factor (VEGF)-dependent migratory response of neural progenitors that also impacts on their neuronal differentiation. The Rho-family GTPases cdc42/Rac1 and Lis1 are major partners of IQGAP1 in this migratory process. Finally, astrocytes of the neurogenic SVZ and RMS are shown to express VEGF. We propose that VEGF synthesized by astrocytes could be involved in the guidance of neural progenitors to neurogenic niches and that IQGAP1 is an effector of the VEGF-dependent migratory signal.

Key words: adult neurogenesis; IQGAP1; migration; neural progenitors; Rac1/Cdc42; VEGF

\section{Introduction}

Neurogenesis persists in the adult mammalian brain in restricted proliferative zones, including the anterior subventricular zone (aSVZ) of the lateral wall of the lateral ventricles (Temple and Alvarez-Buylla, 1999). Three major cell types constitute the neurogenic subependymal layer (Doetsch et al., 1997; Alvarez-Buylla and Garcia-Verdugo, 2002). These are GFAP+ cells, which are the neural stem cells in this brain region (also called type B cells). Type B cells give rise to multipotent neural progenitors, designated type $\mathrm{C}$ cells, which lack morphological or immunohistochemical characteristics of either glia or neuroblasts. After several cycles of division, type $\mathrm{C}$ cells migrate into niches delimited by

Received Sept. 26, 2006; accepted March 16, 2007.

This work was supported by grants from the Association pour la Recherche sur le Cancer (4725), la Région Rhône Alpes (Emergence 8HCO4H00), and I'Institut National du Cancer (PL114). We thank Prof. J. LaMarre (University of Guelph, Guelph, Ontario, Canada) for critical reading of this manuscript, Dr. Daniel Vittet (Institut National de la Santé et de la Recherche Médicale U878, Grenoble, France) for the gift of VEGF-A and stimulating discussions, N. Bertacchi for animal genotyping, and N. Assard for technical assistance.

Correspondence should be addressed to Dr. Jacques Baudier, Unité 873/Transduction du Signal-Institut de Recherche en Technologies et Sciences pour le Vivant, Commissariat à l'Energie Atomique Grenoble, 17 rue des Martyrs, 38054 Grenoble Cedex 9, France. E-mail: jbaudier@cea.fr.

D01:10.1523/JNEUROSCI.0830-07.2007

Copyright $\odot 2007$ Society for Neuroscience $\quad$ 0270-6474/07/274716-09\$15.00/0 astrocyte processes to differentiate into neuronal precursors (type A cells) that express the cell-surface adhesion molecule poly sialic acid-neural cell adhesion molecule (PSA-NCAM). Type A cell chains coalesce in the proximal rostral extension (RE) of the aSVZ, forming a restricted path called the rostral migratory stream (RMS), and migrate to the olfactory bulb (OB) where they differentiate into interneurons (Lois and Alvarez-Buylla, 1994). Recent studies have shown that stem cells and neural progenitors are not exclusively confined to the SVZ but are also present in the entire RMS, including the distal portion within the OB (Gritti et al., 2002). Little is known about the signals that promote proliferation of neural progenitors, their directed migration toward glial tunnels, and their subsequent differentiation into neuronal precursors. Vascular endothelial growth factor (VEGF) has been implicated in these different aspects of neural progenitor biology (Jin et al., 2002, 2003; Zhang et al., 2003; Cao et al., 2004; Schanzer et al., 2004; Hashimoto et al., 2006). VEGF may act indirectly on endothelial cells or astrocytes to influence neuronal cell population (Louissaint et al., 2002; Shen et al., 2004) or directly on neural progenitor cells that express VEGF receptors (Jin et al., 2002; Rosenstein et al., 2003; Zhang et al., 2003; Schanzer et al., 2004; Hashimoto et al., 2006). Characterization of VEGF signal- 
ing in neural progenitors may help to clarify the function of VEGF in adult mammalian neurogenesis.

Here, we first identify the IQGAP1 as a new marker of amplifying neural progenitors and neuronal precursors in the adult mouse brain. IQGAP1 belongs to the IQGAP family of scaffolding proteins, abundant in epithelial and endothelial cells, that binds to a diverse array of signaling and structural molecules (for review see, Brown and Sacks, 2006). By interacting with its target proteins, IQGAP1 participates in multiple cellular functions, including cell-cell adhesion (Lui et al., 2005; Noritake et al., 2005) and migration (Fukata et al., 2002; Mataraza et al., 2003; Yamaoka-Tojo et al., 2004; Kholmanskikh et al., 2006). We next show that in brain, the absence of IQGAP1 delays transition of de novo neural progenitors into neuronal precursor cells. In vitro, IQGAP1 is demonstrated to be a downstream effector of the VEGF-dependent motility response of neural progenitor cells. We propose that IQGAP1 could be an important part of the VEGF signaling pathway involved in the guidance of neural progenitors to neurogenic niches for neuronal differentiation.

\section{Materials and Methods}

Animals. Germline Iqgap1-null mutant mice were generated previously by Li et al. (2000) and maintained on an SV-129 background. Double heterozygous mice were crossed to produce deficient (Iqgap1-/-) and wild-type animals. Animals were genotyped by PCR-based assays according to standard protocols used by Li et al. (2000).

Antibodies. The following primary antibodies were used: IQGAP1(H109) (rabbit polyclonal; Santa Cruz Biotechnology, Tebu-bio, France); Nestin (mouse monoclonal IgG; Developmental Studies Hybridoma Bank, Iowa City, IA); GFAP [mouse monoclonal IgG (Chemicon, Euromedex, France), chicken polyclonal (Abcam, Paris, France), rabbit polyclonal IgG (Dako Cytomation, Trappes, France)]; VEGF (rabbit polyclonal; Abcam); VEGFR-2 (Flk-1) (rabbit polyclonal; Santa Cruz Biotechnology); bromodeoxyuridine (BrdU; rat monoclonal; AdB Serotec, Raleigh, NC); Ki-67 (mouse monoclonal IgG; Abcys, Paris, France); PSA-NCAM (mouse monoclonal IgM; Abcys); Tuj-1 (or $\beta$ III-tubulin) (rabbit polyclonal; Eurogentec, Angers, France); O4 (mouse monoclonal IgM; home-made hybridoma medium); Rac-1 (mouse monoclonal; BD Biosciences, Le Pont de Claix, France); Cdc-42 (mouse monoclonal; BD Biosciences); and $\beta$-catenin (mouse monoclonal; BD Biosciences). Secondary anti-mouse and anti-rat antibodies conjugated to cyanin 3 or cyanin 5 were from Jackson ImmunoResearch (Interchim, Montlucon, France). Secondary anti-mouse and anti-rat antibodies conjugated to Alexa Fluor 488 were from Invitrogen (Cergy Pontoise, France). Secondary anti-chicken polyclonal-IgY-ab6569 was from Abcam.

Immunohistochemistry. Three-month-old animals were deeply anesthetized and killed by transcardial perfusion of saline solution $(150 \mathrm{~mm}$ $\mathrm{NaCl}$ ), followed by $4 \%$ paraformaldehyde. After $24 \mathrm{~h}$ in $4 \%$ paraformaldehyde, brains were cryopreserved, and $14 \mu \mathrm{m}$ sagittal and $20 \mu \mathrm{m}$ coronal cryostat (CM 3000; Leica, Nussloch, Germany) sections were cut. Cryosections were permeabilized in Tris-buffered saline (TBS) containing $0.2 \%$ Triton X-100 and blocked in 5\% normal goat serum (NGS)TBS. After incubation with primary antibodies in NGS-TBS overnight at $4^{\circ} \mathrm{C}$, sections were washed in TBS and stained with the appropriate secondary antibodies. Sections were counterstained with nuclear marker Hoechst $33258(1 \mu \mathrm{g} / \mathrm{ml})$. Images were obtained with a Zeiss (Oberkochen, Germany) Axiovert 200M microscope and with a Leica TCS SP2 confocal microscope.

Immunocytochemistry. Cells were plated onto poly-L-lysine (Sigma, St. Louis, MO)-coated glass coverslips, washed in PBS, fixed with $4 \%$ paraformaldehyde in PBS, and permeabilized with $0.2 \%$ Triton X-100. After incubation with primary antibodies in NGS-TBS overnight at $4^{\circ} \mathrm{C}$, cells were washed in TBS and stained with the appropriate secondary antibodies.

BrdU administration and labeling. Different protocols of BrdU (SigmaAldrich, Lyon, France) intraperitoneal injections were performed (100 $\mathrm{mg} / \mathrm{kg}$ body weight) to label different dividing cell populations: (1) a
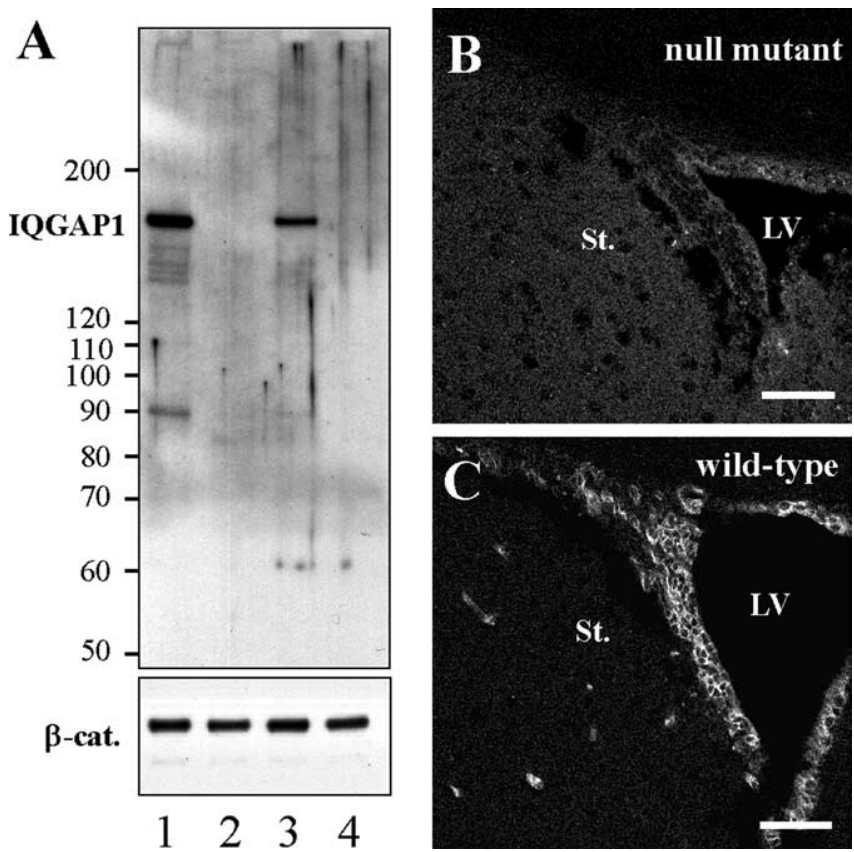

Figure 1. Characterization of IQGAP1 protein in the mouse brain. $A$, Western blot analysis of IQGAP1 protein in mouse brain. Brain extracts derived from the SVZ (lanes 1,2) and the brain parenchyma (lanes 3,4) of wild-type (lanes 1,3 ) and null-mutant (lanes 2,4$)$ mice were analyzed with anti-IQGAP1 and anti- $\beta$-catenin ( $\beta$-cat.) antibodies. Values on the left are in kilodaltons. $\boldsymbol{B}, \boldsymbol{C}$, Indirect immunofluorescence analysis of IQGAP1 immunoreactivity in the aSVZ of lqgap 1-null ( $\boldsymbol{B}$ ) and wild-type (C) mice. LV, Lateral ventricle; St., striatum. Scale bars, $50 \mu \mathrm{m}$.

single injection, $30 \mathrm{~min}$ before the animals were killed, that preferentially labels rapidly dividing "type C" cells; and (2) three successive injections (one per hour), with the animals being killed $1 \mathrm{~h}$ after the last injection, to label an important pool of S-phase cycling cells. For counting experiments, serial sections in the aSVZ were selected. For quantitative analysis of the percentage of BrdU+/PSA-NCAM - and BrdU+/PSA-NCAM+ cells, two wild-type and Iqgap1-null mice from the same litter were given injections of BrdU three times (one per hour) and killed $1 \mathrm{~h}$ after the last injection. From each animal, we selected 5-10 serial sections in four different precise regions extending rostrocaudally from the $\mathrm{OB}$ to the lateral ventricles. Presented results are the average of four independent experiments. After fixation and cryosectioning, brain slices were permeabilized as describe above, incubated in $2 \mathrm{~N} \mathrm{HCl}$ at room temperature, neutralized in $0.1 \mathrm{~m}$ sodium borate buffer, and washed in TBS buffer. Immunohistochemical staining was performed as describe above.

Neurosphere culture and differentiation. Null-mutant and wild-type mice were killed by cervical dislocation. Brains were removed and placed in PBS, and the ventricular walls were dissected, transferred in dissociation medium containing trypsin ( $5000 \mathrm{U}$; Sigma), $0.67 \mathrm{mg} / \mathrm{ml}$ hyaluronidase (2000 U/mg; Sigma), and 0,2 mg/ml kynurenic acid (Sigma), and kept $30 \mathrm{~min}$ in an incubator $\left(37^{\circ} \mathrm{C}, 5 \% \mathrm{CO}_{2}\right)$. Tissues were washed in DMEM with $20 \%$ fetal bovine serum (FBS) to inactivate the enzyme activity and carefully triturated with a Pasteur glass pipette. After homogenization, cells were centrifuged and resuspended in basal neurosphere medium (DMEM, F-12, B27, and 0.1\% BSA) complemented with both epidermal growth factor (EGF) and basic fibroblast growth factor (bFGF) mitogens (20 ng/ml) (Gritti et al. 2002). To assess cell multipotencies, cells were plated onto poly-L-lysine (Sigma)-coated glass coverslips or onto poly-L-lysine-coated permanox plastic (LabTek, Campbell, CA). Differentiation experiments were performed between 1 and $15 \mathrm{~d}$ in vitro (DIV) in basal medium in the presence of $3 \%$ FBS. To examine VEGF-A (165) (Abcys) effects onto adult neurospheres, dissociated cells from primary neurospheres were first expanded 3 DIV in neurosphere proliferation medium as defined above. After three extensive washings with basal neurosphere medium, neurospheres were plated on poly-Llysine-coated glass-bottom dishes and cultivated in basal medium with 
N2-complement (Invitrogen, Cergy Pontoise Cedex, France) supplemented with only VEGF-A $(20 \mathrm{ng} / \mathrm{ml})$.

Video microscopy. For time-lapse microscopy, secondary neurospheres derived from adult wild-type and Iqgap1-null mice were transferred to poly-L-lysine-coated glassbottom dishes covered by a membrane permeable to $\mathrm{CO}_{2}$ in the absence or presence of VEGF-A $(20 \mathrm{ng} / \mathrm{ml})$ and placed inside the video microscopy platform equipped with a device enabling regulation of temperature and $\mathrm{CO}_{2}$ level.

Time lapse of $Z$-series images $(Z=13)$ for multiple positions $(n=10)$ were collected with an inverted motorized microscope (Axiovert 200M; Zeiss) controlled by MetaMorph software (Universal Imaging, Downingtown, PA). Cells were observed with a plan neofluar objective (20×, 0.5 numerical aperture), and phasecontrast images were acquired with a CoolSnap HQ charge-coupled device camera (Roper Scientific, Trenton, NJ) either every 2 min or every $5 \mathrm{~min}$ for $6 \mathrm{~h}$ with an acquisition time of $25 \mathrm{~ms}$ under a low halogen illumination to avoid cell damage. For each $Z$-series image, the best focus was chosen before the reconstitution of the movie. To quantify a migration distance, the respective moving of a cell and the neurosphere centroïd were considered. The relative migration distances were expressed as mean \pm SEM.

Immunoprecipitation. Cells were lysed on ice in lysis buffer (50 mM Tris, $\mathrm{pH} 8.0,150 \mathrm{~mm}$ $\mathrm{NaCl}, 0.5 \%$ Triton $\mathrm{X}-100$, and 2 mM EDTA/ EGTA) supplemented with phosphatase inhibitor and protease inhibitor mixtures. Lysates were passed through a 26 gauge needle $(15 \times)$ and centrifuged to remove insoluble material. Supernatants were either boiled in $1 \times$ DTT Laemlli buffer (total cell lysates) or incubated with anti-IQGAP1 antibodies together with protein A-Sepharose (Amersham Biosciences, Piscataway, NJ) for $30 \mathrm{~min}$ rotating at $4^{\circ} \mathrm{C}$. The immunoprecipitates were washed three times in lysis buffer and transferred to a new Eppendorf tube, and the beads were boiled in $1 \times$ Laemlli with 20 mm DTT. Proteins were separated by SDS-PAGE using 6 or $10 \%$ polyacrylamide concentrations. Proteins were blotted onto nitrocellulose membranes.

Reverse transcription-PCR from adult neurospheres. Total RNA was extracted with Trizol solution (Invitrogen), and cDNA was isolated using the SuperScript First Strand kit (Invitrogen). One microgram of RNA was used to synthesize cDNA with oligo-(dT) 12-18 primers and $1 \mu \mathrm{l}$ of SuperScript II reverse transcriptase and was pursued according to manufacturer's instructions. For PCR $\left(95^{\circ} \mathrm{C}>45 \mathrm{~s}, 57^{\circ} \mathrm{C}>25 \mathrm{~s}, 72^{\circ} \mathrm{C}>50 \mathrm{~s}\right.$, 40 cycles) experiments, $1 \mu \mathrm{l}$ of cDNA was used to amplify specific sequences for Flt-1 (forward, 5'-CATGCCTCTGGCCACTTG-3'; reverse, 5' CTCTGATGGTGATCGTGG-3') and Flk-1 (forward, 5' -TGGCATCAAGGAAGTGTATCC-3'; reverse, 5' -TATTTCCCAGAGCAACACACC-3').

Statistical analyses. Data were statistically analyzed using Student's $t$ test or ANOVA as appropriate (Prism 4.03; Graph Pad, San Diego, CA). Minimal statistical significance for each test used was defined at $p<0.05$.

\section{Results}

IQGAP1 is expressed by neural progenitor and precursor cells in the subventricular germinal zone and the RMS in the adult mouse brain

Affinity-purified antibodies against an N-terminal epitope were used to probe IQGAP protein expression in brain extracts derived from wild-type and Iqgap1-null mice (Fig. 1A). The antibodies recognize a single protein band with the molecular mass corresponding to IQGAP1 $\left(M_{\mathrm{r}} 180 \mathrm{kDa}\right)$. The protein band is not detected in extracts derived from Iqgap1-null mice. In wild-type brain, the IQGAP1 protein is most abundant in extracts obtained from the SVZ.

To investigate the cellular expression of IQGAP1 protein in adult mouse brain, we compared the immunostaining pattern observed with IQGAP1 antibodies in Iqgap1-null mice and wildtype animals (Fig. $1 B, C$ ). The IQGAP1 immunoreactivity is completely absent in Iqgap 1-null mice, confirming the specificity of the antibodies (Fig. $1 \mathrm{~B}$ ). In the brain of wild-type animals, IQGAP1 antibodies stain the endothelial cells, whereas there is no labeling of astrocytes, oligodendrocytes, and neuronal cell soma. In the SVZ, strong IQGAP1 immunoreactivity is associated with the plasma membrane of the epithelial ependymal cells that form the walls of the brain ventricles and with dense clusters of cells that appose the ependymal cell layer in the aSVZ (Fig. 1C).

To identify the IQGAP1 + cells in the aSVZ, brain slices were triple immunostained for IQGAP1, GFAP, and the type A cell specific antigen PSA-NCAM (Fig. 2A,B). Results show that PSA$\mathrm{NCAM}+$ cells ensheathed within GFAP + astrocyte processes express IQGAP1 (Fig. $2 A$ ). There are also individual or small clusters of IQGAP1+/PSA-NCAM - cells isolated from type A cells by astrocyte processes (Fig. $2 A$, arrowheads). The IQGAP1+/ PSA-NCAM - cells often appear as mitotic cells (Fig. $2 B$, arrowheads) and are strongly labeled with BrdU after a 30 min BrdU pulse (Fig. 2C, arrowheads). All of these characteristics are fea- 


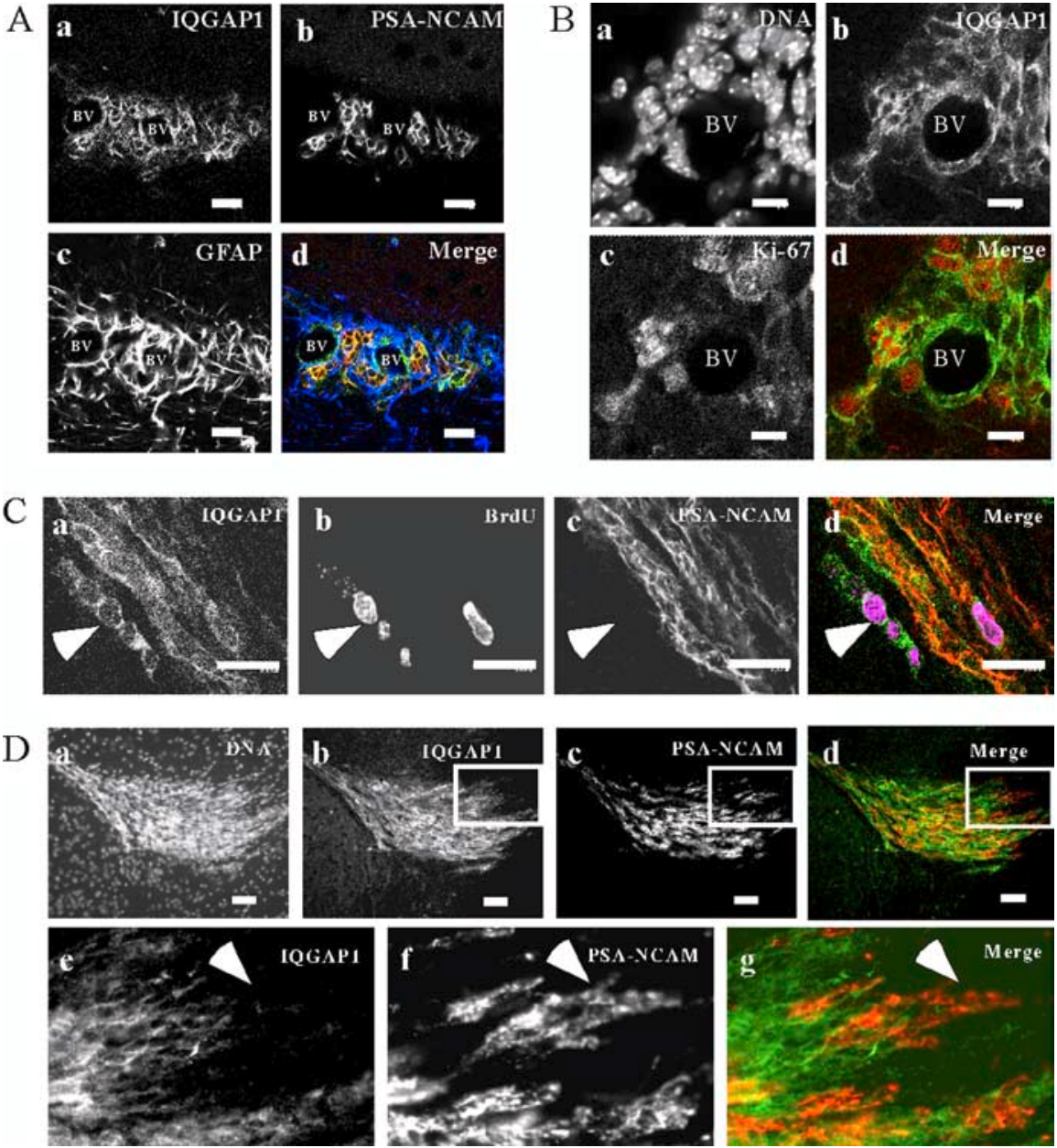

Figure 3. Characterization of the IQGAP1-positive cells in the proximal RE of the SVZ and the RMS. $A$, A coronal section focused on the proximal RE triple immunostained with IQGAP1 $(\boldsymbol{a}, \boldsymbol{d}), \operatorname{PSA} \operatorname{NCAM}(\boldsymbol{b}, \boldsymbol{d})$, and GFAP $(\boldsymbol{c}, \boldsymbol{d})$ antibodies shows that IQGAP1+ PSA-NCAM + type A cells ensheathed within glial processes accumulate around blood vessels (BV) (d). $\boldsymbol{B}$, Triple immunostaining with Hoechst for DNA ( $\boldsymbol{a})$, IQGAP1 antibodies $(\boldsymbol{b}, \boldsymbol{d})$, and Ki-67 antibody $(\boldsymbol{c}, \boldsymbol{d})$ shows that IQGAP1 + cells are Ki-67+. C, Sagittal section in the RMS of a mouse given injections of BrdU for 30 min triple immunostained with IQGAP1 $(\boldsymbol{a}, \boldsymbol{d}), \operatorname{BrdU}(\boldsymbol{b}, \boldsymbol{d})$, and PSA-NCAM ( $\boldsymbol{c}, \boldsymbol{d})$ antibodies. IQGAP1 + cells lining the chains of PSA-NCAM + neuroblasts (arrowheads) are colabeled with BrdU (d). D, Sagittal section in the most distal part of the RMS stained with Hoechst for DNA (a) and double immunostained with IQGAP1 antibodies $(\boldsymbol{b}, \boldsymbol{d}, \boldsymbol{e}, \boldsymbol{g})$ and PSA-NCAM antibody $(\boldsymbol{c}, \boldsymbol{d}, \boldsymbol{f}, \boldsymbol{g}) . \boldsymbol{e}-\boldsymbol{g}$ are enlargements of the boxed areas in $\boldsymbol{b}-\boldsymbol{d}$, respectively. The arrowheads point to IQGAP1-/PSA-NCAM+ migrating neuroblasts. Scale bars: $A, C, 20 \mu \mathrm{m} ; \boldsymbol{B}, 10 \mu \mathrm{m} ; \boldsymbol{D}, 50 \mu \mathrm{m}$. BV, Blood vessels.

tures of neurogenic progenitors (type C cells) (Doetsch et al., 1997; Alvarez-Buylla and Garcia-Verdugo, 2002).

IQGAP1 immunoreactivity persists in the entire RMS (Fig. 3). In the proximal RE, the IQGAP1+ cells are often found ensheathed through glial processes in close association with blood vessels (Fig. $3 A, B$ ). Within these perivascular niches, the IQGAP1 + cells are immunopositive for PSA-NCAM (Fig. 3A) and $\mathrm{Ki}-67$ antigen that specify proliferating cells (Fig. $3 B$ ). Within the RMS, IQGAP1+/PSA-NCAM - cells can also be found as clusters lining the chains of PSA-NCAM+ precursors (Fig. 3C, arrowheads). These IQGAP1+/PSA-NCAM - cells are labeled with BrdU after a $30 \mathrm{~min}$ BrdU pulse and may thus correspond to the neural progenitors cells that reside within the RMS (Gritti et al., 2002). In the most distal part of the RMS, IQGAP1 immunoreactivity persists into neural progenitor (PSA-NCAM-) and precursor (PSA-NCAM+) cells (Fig. 3D). In this region, IQGAP1 immunoreactivity markedly decreases in PSA-NCAM+ neuroblasts that migrate to the $\mathrm{OB}$ (Fig. $3 D e-D g$ ).

Together, our immunohistochemistry studies identify IQ-
GAP1 as a new marker of amplifying neural progenitors and neuronal precursors in the adult mouse brain.

Iqgap1-null mice show apparent delay in differentiation of neural progenitors Comparison of wild-type and Iqgap1-null mouse brain revealed no apparent phenotype associated with the cellular organization of the SVZ, the RE of the SVZ, the RMS, and the OB. Because IQGAP1 is preferentially expressed in proliferating cells, we examined whether IQGAP1 could play a role in the control of neural progenitor and precursor cell proliferation. Wildtype and Iqgap1-null mice were given injections of BrdU and killed $30 \mathrm{~min}$ after injection. With $30 \mathrm{~min}$ pulse labeling, neural progenitors are preferentially labeled (Doetsch et al., 1997). Counting the number of BrdU-labeled cells in the SVZ revealed no significant difference between wild-type and mutant mice (data not shown). The same result was obtained with mice that received three successive BrdU injections (one per hour), with animals being killed $1 \mathrm{~h}$ after the last injection (data not shown). These results suggest that the absence of IQGAP1 does not affect neural progenitor and precursor cell proliferation. However, significant differences between wild-type and null-mutant mice were revealed by comparing the ratio of $d e$ novo amplifying neural progenitor $(\mathrm{BrdU}+/ \mathrm{PSA}-\mathrm{NCAM}-)$ and neuronal precursor (BrdU+/PSA-NCAM+) cells (Fig. 4). In these studies, wild-type and Iqgap1-null mice from the same litter received three successive BrdU injections (one per hour) with the animals being killed $1 \mathrm{~h}$ after the last injection. Serial sections extending rostrocaudally from $\mathrm{OB}$ to lateral ventricles were double immunostained with BrdU and PSA-NCAM antibodies. Representative immunostaining of sections in the proximal RE (Fig. $4 A a, A c$ ) and the RMS (Fig. $4 A b, A d$ ) of wild-type and Iqgap 1-null mice show that both neural progenitor (PSA-NCAM - ) and neuronal precursor (PSA-NCAM+) cells incorporated BrdU. BrdU-labeled neural progenitors can also be distinguished from BrdU-labeled neuronal precursor cells by their large irregular nuclei (arrowhead in panel c) and their localization at the periphery of the chains of migrating PSA-NCAM + cells (Fig. 4Ac, arrowheads) (Doetsch et al., 1997). Analysis of the ratio between BrdU+/PSA-NCAMand BrdU +/PSA-NCAM + in wild-type and null-mutant mice revealed that Iqgap1-null mice have twice the number of BrdU+/PSA-NCAM - cells than their wild-type counterparts (Fig. $4 B$ ). These observations suggest that the absence of IQGAP1 delays differentiation of neural progenitors. Such apparent delay in differentiation might be an intrinsic property of Iqgap 1-null neural progenitors or could result from altered migration of neural progenitors to neurogenic niches for neuroblast differentiation. 

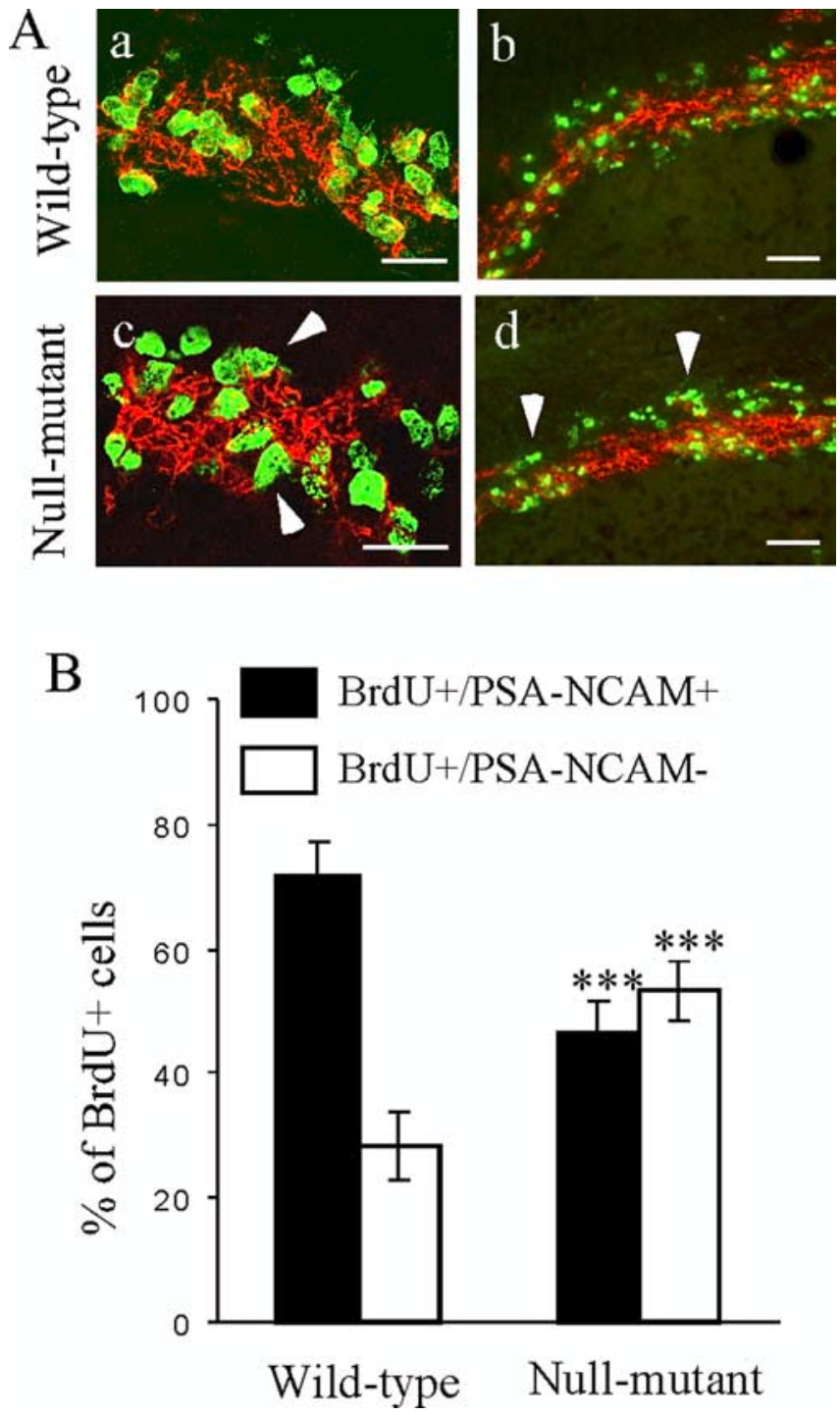

Figure 4. Iggap 1- null mice show accumulation of neural progenitors. $\boldsymbol{A}, \boldsymbol{B}$, Wild-type and lqgap 1-null mice from the same litter were given injections of BrdU three times (once per hour) and killed $1 \mathrm{~h}$ after the last injection. $A$, Representative double immunostaining for BrdU (green) and PSA-NCAM (red) on sagittal sections in the proximal RE $(\boldsymbol{a}, \boldsymbol{c})$ and the RMS $(\boldsymbol{b}, \boldsymbol{d})$ of wildtype $(\boldsymbol{a}, \boldsymbol{b})$ and lqgap 1-null $(\boldsymbol{c}, \boldsymbol{d})$ mice. Arrowheads point to BrdU + cells with neural progenitor features. Scale bars: $\boldsymbol{a}, \boldsymbol{c}, 20 \mu \mathrm{m} ; \boldsymbol{b}, \boldsymbol{d}, 50 \mu \mathrm{m}$. $\boldsymbol{B}$, Quantitative analysis of the percentage of BrdU +/PSA-NCAM - and BrdU +/PSA-NCAM + cells in wild-type and lqgap1-null mice. Results represent the average of four independent experiments. A total of $8001 \mathrm{BrdU}+$ cells in wild-type animals and 7615 BrdU + cells in Iqgap 1-null mice were analyzed. Significant differences from the corresponding wild-type counterpart were determined by Student's $t$ test $\left({ }^{* * *} p<0.005\right)$. Error bars indicate SEM.

\section{IQGAP1 regulates VEGF-triggered neural progenitor migration in vitro}

To shed light on specific functions of IQGAP1 in neural progenitor migration/differentiation, we performed in vitro studies using neural progenitors grown as neurospheres. Neural progenitors have been isolated from adult wild-type and Iqgap1-null mice SVZ and grown as neurospheres as described previously (Gritti et al., 2002). We first confirmed the expression of IQGAP1 protein in neural progenitors by indirect immunofluorescence and Western blot and controled the absence of IQGAP1 immunoreactivity in neurospheres derived from Iqgap1-null mice (see supplemental Fig. 2A, $B$, available at www.jneurosci.org as supplemental material). We next compared the proliferation and differentiation properties of wild-type and Iqgap1-null cells. Analysis of cell-cycle duration on secondary neurospheres revealed no significant differences between wild-type and mutant cells (data not shown), confirming the in vivo observation that IQGAP1 does not markedly affect on neural progenitor cell proliferation.

We also investigated the intrinsic migration and differentiation capacities of neural progenitors after withdrawal of EGF and bFGF in low-serum-containing medium (Gritti et al., 2002; Shen et al., 2004). When plated onto poly-lysine-coated glass slides, control and mutant neurospheres attached to the substratum and progressively formed a monolayer (supplemental Fig. $1 \mathrm{~A}$, available at www.jneurosci.org as supplemental material). There was no difference between wild-type and mutant cells. For $15 \mathrm{~d}$, we analyzed the kinetics of differentiation as well as the percentage of neurons (Tuj-1+), astrocytes (GFAP + ), or oligodendrocytes $(\mathrm{O} 4+)$ produced by wild-type and Iqgap1-null cells. Results show that progenitor differentiation capacity and specification are not dependent on IQGAP1 (supplemental Fig. 1B, $C$, available at www.jneurosci.org as supplemental material).

Because IQGAP1 has recognized functions in cell motility signal transduction (Fukata et al., 2002; Briggs and Sacks, 2003; Mataraza et al., 2003; Kholmanskikh et al., 2006), we next investigated whether IQGAP1 could function as a regulator of VEGFtriggered neural progenitor migration (Zhang et al., 2003). As found previously with rat SVZ neural progenitors (Zhang et al., 2003), mouse wild-type and mutant neural progenitors do express VEGF-A receptor 1 (VEGF-R1) (Flt1) and VEGF-R2 (Flk1) (Fig. 5A). The VEGF-R2 specifically mediates the chemotactic activities of VEGF in rat neural progenitors (Zhang et al., 2003). We used time-lapse video microscopy to compare the behavior of wild-type and Iqgap1-deficient neurospheres plated onto polylysine-coated glass slides in medium depleted of EGF and bFGF but supplemented with physiological VEGF concentration (20 $\mathrm{ng} / \mathrm{ml}$ ). Clear-cut differences between wild-type and Iqgap1-null cells were observed (Fig. 5B and supplemental videos 1 and 2, available at www.jneurosci.org as supplemental material). Wildtype cells displayed strong positive VEGF-dependent chemokinesis as revealed by dynamic spreading from the neurospheres. Quantitative analysis on 10 individual cell showed an average migration distance of $95 \pm 7 \mu \mathrm{M}$ after $6 \mathrm{~h}$ (Fig. 5C). In contrast, Iqgap1-null neurospheres attached to the substratum without apparent dynamic migratory process during the time of the experiment. The migratory response of wild-type cells to VEGF was totally blocked in the presence of VEGF-R2 inhibitor SU1498 (50 $\mu \mathrm{M}$ ) (Strawn et al., 1996) (data not shown). These data show that IQGAP1 protein is a key downstream effector in the VEGFinduced chemokinetic response of undifferentiated neural progenitor cells.

\section{IQGAP1 regulates VEGF-triggered neuronal differentiation in vitro}

To determine the fate of the neurosphere cells migrating in response to VEGF, we performed immunocytochemical characterization of the wild-type neurospheres after 2, 8, and 24 h of VEGF stimulation. Neurosphere cells were double immunostained with Tuj-1 antibodies that label cells committed to neuronal differentiation and either NG2 antibodies that strictly label multipotent progenitor cells in vitro (Fig. 6A) or nestin antibodies that label both multipotent progenitors and neuronal precursors (Fig. $6 B, C)$. Results showed that cells that migrated out of the neurospheres were NG2 + but rapidly lost NG2 immunoreactivity and became Tuj-1+ (Fig. $6 A d-A f$ ). After 8 h, NG2 immunoreactivity 
A

Flk-1

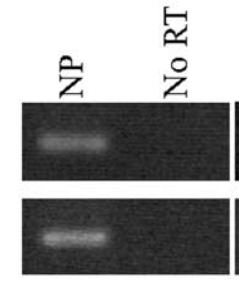

Wild-type

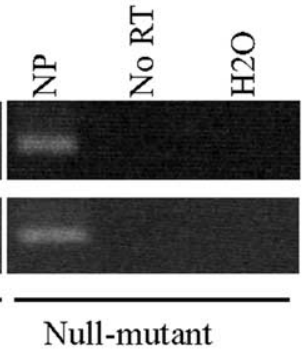

$\mathrm{C}$

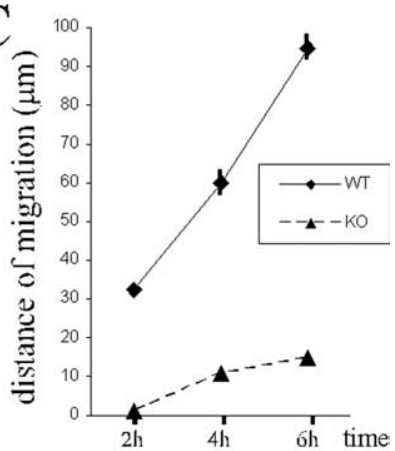

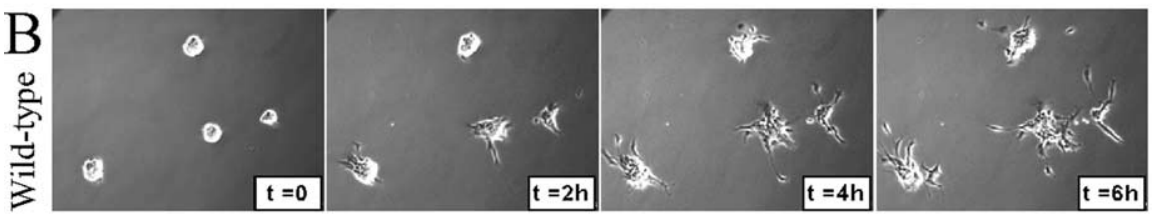

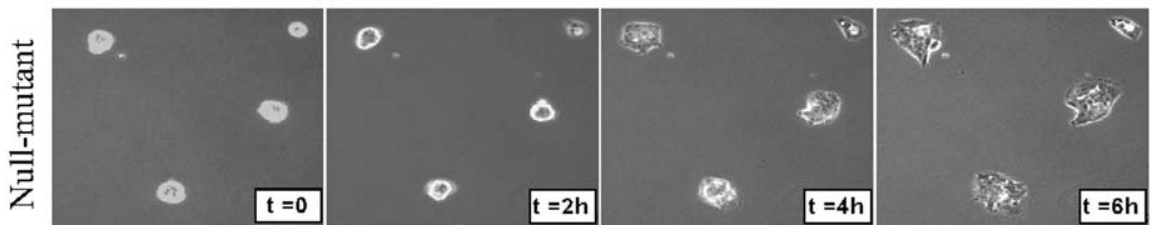

Figure 5. IQGAP1 regulates VEGF-dependent neural progenitor cell migration. $\boldsymbol{A}$, Reverse transcription-PCR (RT) analysis performed on wild-type and lqgap 1-null mutant neurospheres reveal expression of both VEGF receptors Flk-1 (VEGF-R2) and Flt-1 (VEGF-R1). NP, Neural progenitors. B, Phase-contrast reconstitution of time-lapse imaging of wild-type and lagap1-null mutantderived neurospheres in response to VEGF $(20 \mathrm{ng} / \mathrm{ml})$ stimulation. C, Quantification of the average migration distance $(n=10)$ of wild-type (WT) and lggap1-null (KO) neurosphere cells after VEGF stimulation.

is residual, and most of the cells adopted a neuronal fate (Fig. $6 A g-A i)$. Double immunostaining with nestin and Tuj-1 antibodies revealed that migrating cells in the outgrowth zone of neurospheres were nestin + and rapidly acquired a mixed nestin $+/$ Tuj- $1+$ phenotype (Fig. $6 B, C$ ). The nestin $+/$ Tuj-1+ cells could represent the neuronal precursor stage. After $24 \mathrm{~h}$, nearly $70 \%$ of the cells differentiated into nestin $-/$ Tuj- $1+$ neuroblasts (Fig. $6 B, C$ ). In contrast to differentiation induced in low-serum-containing medium, VEGF stimulation does not induce astrocyte $(\mathrm{GFAP}+)$ or oligodendrocyte $(\mathrm{O} 4+)$ differentiation (data not shown).

We next compared the effects of VEGF-A on the timing of neuronal differentiation of wild-type and Iqgap1-null neurosphere cells (Fig. 6C,D). Quantitative analysis revealed that the timing for neuronal differentiation is severely delayed in Iqgap 1null neurospheres compared with wild-type cells (Fig. 6C,D). Thus, IQGAP1 regulates VEGF-triggered neural progenitor migration that also impacts on neuronal differentiation in vitro.

\section{Cdc42/Rac1 Rho GTPases are major partners of IQGAP1 in VEGF-dependent migratory signaling pathway}

To investigate the underlying molecular mechanisms involved in the VEGF-dependent migratory response, we examined the interaction of IQGAP1 with recognized targets involved in cell motility and migration, including the Rho-family GTPases Rac1 and Cdc42 (Fukata et al., 2002; Mataraza et al., 2003; Kholmanskikh et al., 2006). We first analyzed the effect of VEGF stimulation on Rac1 and IQGAP1 subcellular localization by confocal microscopy (Fig. 7A). In control neurospheres, Racl immunostaining clearly defined cell-cell contacts, whereas IQGAP1 immunoreactivity gave more diffuse punctuate staining. After VEGF stim-

ulation, IQGAP1 immunoreactivity relocated to cell-cell contacts where it colocalizes with Rac1. Quantification of the overlapping between red and green pixels on four different neurospheres showed an average twofold increase in VEGF-treated neurospheres. Coimmunoprecipitation studies confirmed that VEGF stimulation significantly enhanced the interaction between IQGAP1 and Rhofamily GTPases with a maximum after a 10 min stimulation (Fig. $7 B$, lanes 2,3 ). The marked enrichment of Cdc42 and Rac1 in IQGAP1 immunoprecipitates compared with total lysate levels clearly identified Cdc42 and Rac1 as major partners for IQGAP1 in neural progenitors.

IQGAP1 in complex with Cdc42 and Racl can serve as a template for the recruitment of additional proteins. In cerebellar granule cells, Lis1 and CLIP-170 contribute to neuronal motility signal transduction by interacting with the IQGAP1/Cdc42/Rac1 complex (Kholmanskikh et al., 2006). In neural progenitors, Lis1 is also found associated with IQGAP1 immunoprecipitates, and that interaction is further stimulated after VEGF stimulation (Fig. $7 B$ and supplemental Fig. $2 B$, available at www.jneurosci.org as supplemental material). Concerning CLIP-170, the very low expression level of this protein in neurosphere cells (supplemental Fig. $2 \mathrm{~A}$, available at www.jneurosci.org as supplemental material) prevented accurate coimmunoprecipitation analysis (supplemental Fig. $2 B$, available at www.jneurosci.org as supplemental material).

\section{Astrocytes of the neurogenic SVZ and the RMS areas express VEGF}

Because VEGF is an attractive guidance cue for the migration of SVZ neural progenitors in vitro (Zhang et al., 2003), it was essential to identify potential sources of VEGF in the germinative SVZ and RMS where neural progenitors reside. Indirect immunofluorescence analysis revealed that, in the adult mouse brain, astrocytes of the SVZ and RMS are characterized by high VEGF immunoreactivity (Fig. $8 \mathrm{~A}$ ) compared with astrocytes of other nonneurogenic brain regions (Fig. $8 B$ ). VEGF synthesis by astrocytes associated with de novo neurogenesis has already been observed during postnatal development of the cerebellum (Acker et al., 2001), in brains subjected to enriched environments and performance in the hippocampus (Cao et al., 2004) and after brain injury (Lee et al., 1999). Thus, specialized astrocytes of the neurogenic regions are an endogenous source of VEGF that might contribute to directed migration of neural progenitors.

\section{Discussion}

Adult neurogenesis is a complex phenomenon that requires integration of numerous intrinsic and extrinsic cues to generate new neurons throughout life. All of these mechanisms are not clearly fully understood. We present here, for the first time, a modulating role of the IQGAP1 scaffolding protein in the context of adult neurogenesis. In the adult mouse brain, IQGAP1 is expressed by the parenchyma endothelial cells, the epithelial 

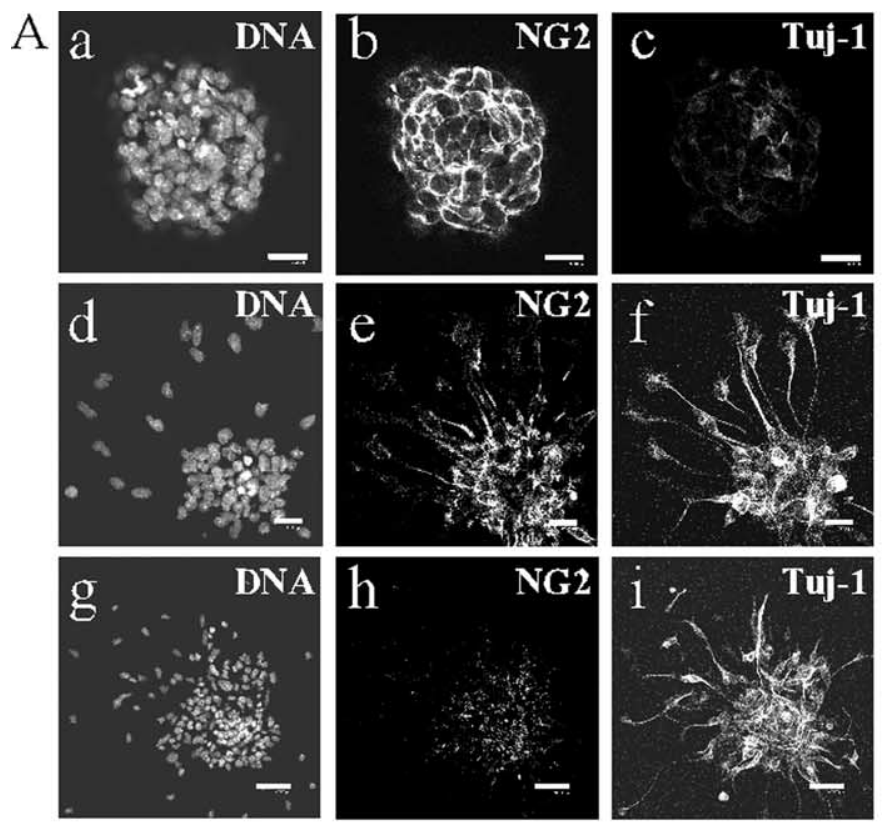
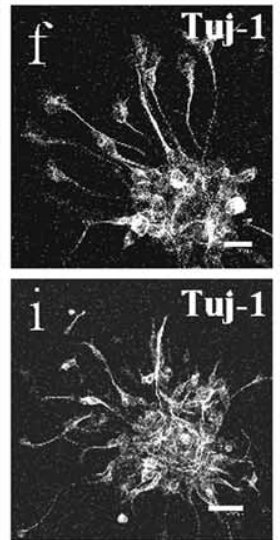
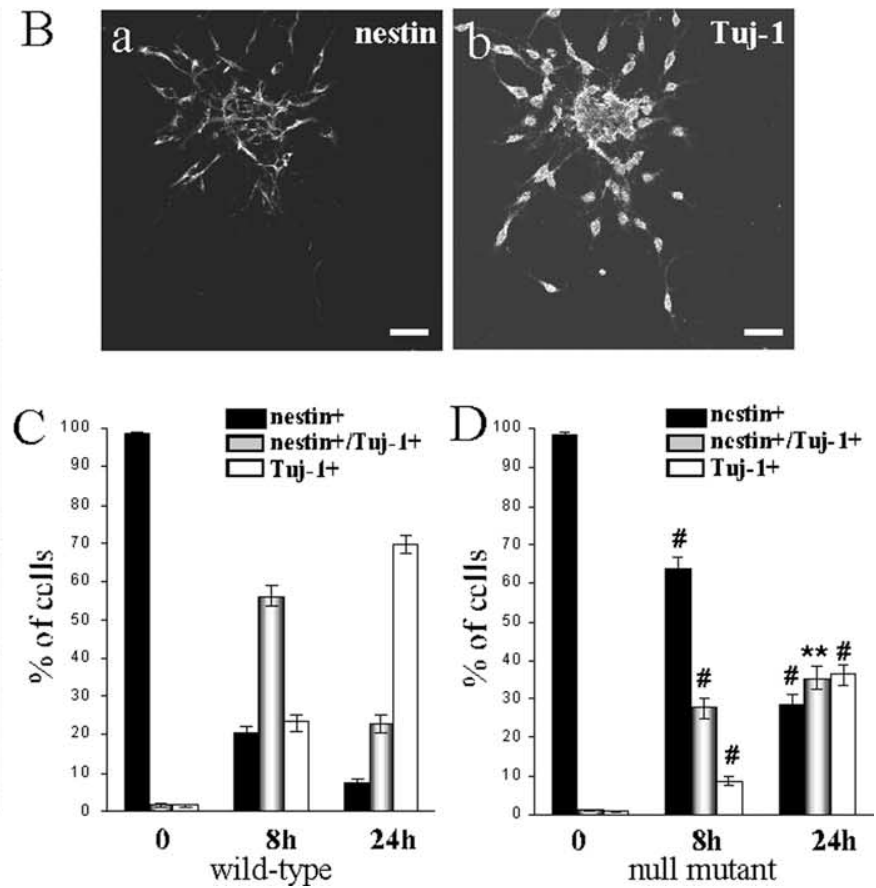

Figure 6. VEGF-dependent neural progenitor chemokinesis correlates with neuronal differentiation. $\boldsymbol{A}$, Wild-type neurospheres were plated on poly-lysine-coated glass slides in a basal medium containing N2 complement and supplemented only with VEGF $(20 \mathrm{ng} / \mathrm{ml})$. Cells were immediately fixed $(\boldsymbol{a}-\boldsymbol{c})$ or left $2 \mathrm{~h}(\boldsymbol{d}-\boldsymbol{f})$ and $8 \mathrm{~h}(\boldsymbol{g}-\boldsymbol{i})$ in the presence of VEGF before fixation. Cells were stained with Hoechst for DNA $(\boldsymbol{a}, \boldsymbol{d}, \boldsymbol{g})$ and double immunostained with anti-NG2 $(\boldsymbol{b}, \boldsymbol{e}, \boldsymbol{h})$ and anti-Tuj-1 $(\boldsymbol{c}, \boldsymbol{f}, \boldsymbol{i})$ antibodies. Scale bars: $\boldsymbol{a}-\boldsymbol{f}, 20 \mu \mathrm{m} ; \boldsymbol{g}$-i, $40 \mu \mathrm{m}$. $\boldsymbol{B}-\boldsymbol{D}$, The effect of VEGF on neuronal differentiation. $\boldsymbol{B}$, Representative wild-type neurospheres stimulated with VEGF for $24 \mathrm{~h}$ and double immunostained with anti-nestin $(\boldsymbol{a})$ and anti-Tuj-1 (b) antibodies. Scale bars, $50 \mu$ m. $\boldsymbol{C}, \boldsymbol{D}$, Comparison of kinetics of neuronal phenotype acquisition between wild-type $(\boldsymbol{C})$ and Iqgap 1-null mutant $(\boldsymbol{D})$ neurospheres. Wild-type and Iqgap 1-null mutant neurospheres were stimulated with VEGF $(20 \mathrm{ng} / \mathrm{ml})$ for 8 and $24 \mathrm{~h}$ and double immunostained with anti-nestin and anti-Tuj- 1 antibodies. Three differentiation stages were identified based on nestin and Tuj- $1 \mathrm{immun}$ ( Results for details). Results are the average of three independent experiments, and significance was determined by comparison to the wild-type counterpart. ${ }^{* *} p<0.01$; $p<0.005$. Error bars indicate SEM.

ependymal cells of the ventricles, and by neural progenitor and neuronal precursor cells in the SVZ and the RMS. To shed light on critical functions for IQGAP1 in neural progenitor cells, we compared properties of wild-type and Iqgap1-null neural progenitors in vivo and in vitro. The major in vivo phenotype that characterizes Iqgap1null mice is an apparent delay in the differentiation of neural progenitors into neuronal precursor cells (Fig. 4). To provide information on the functional role of IQGAP1 in neural progenitors, we used in vitro neurosphere cultures. Comparison of the response of wild-type and Iqgap1-null neural progenitors to VEGF stimulation revealed a role for IQGAP1 in VEGFdependent neural progenitor migration (Fig. 5). VEGF stimulation of wild-type neural progenitors elicited both migratory and neuronal differentiation signals (Fig. $6)$, suggesting that these two phenomenons are coupled. Neuronal differentiation accompanying VEGF-mediated migration is delayed in Iqgap1-null cells (Fig. $6 C, D)$, providing evidence that IQGAP1 has an integral role in the both VEGF-induced responses. Considering the specific expression of the VEGF receptor Flk1 on uncommitted neural progenitors residing in the SVZ in vivo (Jin et al., 2002; Zhang et al., 2003), and our finding that neurosphere cells express Flk1 in vitro, we suggest a possible link between the VEGF signaling path-
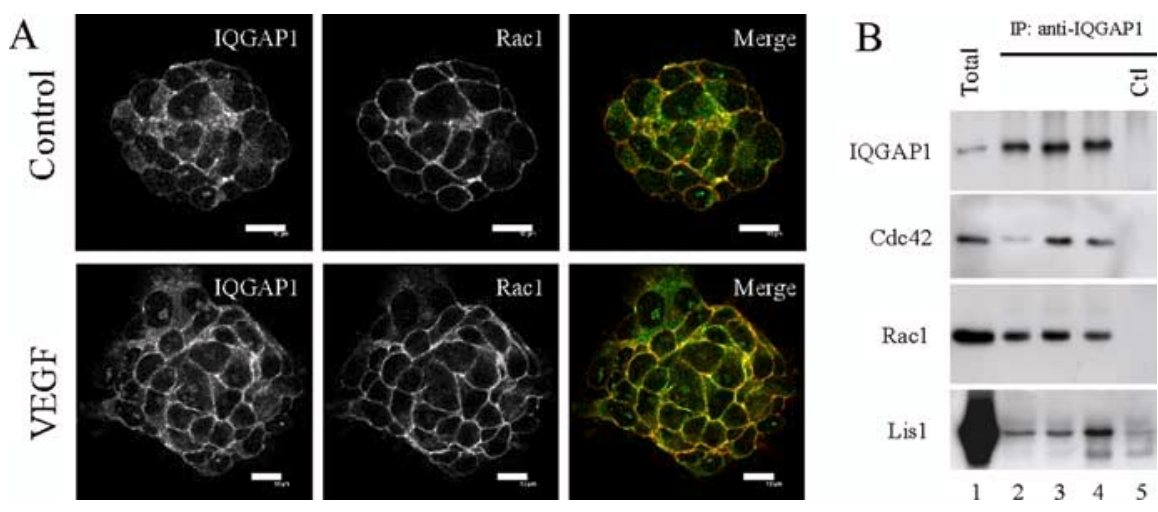

Figure 7. Analysis of IQGAP1 partners in wild-type neurospheres stimulated with VEGF. $\boldsymbol{A}$, VEGF stimulation enhances colocalization of IQGAP1 with Rac1 at the cell membrane. Unstimulated (control) or VEGF-stimulated neurospheres (VEGF) were double immunostained with anti-IQGAP1 (green) and anti-Rac1 (red) antibodies. Scale bars, $10 \mu \mathrm{m}$. B, Characterization of IQGAP1 immunoprecipitates (IP) from neurospheres stimulated with VEGF. Total neurosphere extracts (lane 1) and IQGAP1 immunoprecipitates from neurospheres not stimulated (lane 2) or stimulated with VEGF for 10 min (lanes 3) or 30 min (lanes 4) were analyzed by Western blot with polyclonal IQGAP1 and monoclonal Cdc42, Rac1, and Lis1 antibodies as indicated. Lane 5 is a control (Ctl) lane corresponding to the IQGAP1 immunoprecipitate from iqgap1-null neurospheres.

way and IQGAP1 in neural progenitor migration and differentiation in vivo. The immunohistochemical data showing that VEGF immunoreactivity is confined to the astrocytes of the aSVZ and RMS in mouse brain (Fig. 8), together with the observation that neuronal precursors (IQGAP1+/PSA-NCAM+) are often found forming perivascular niches ensheathed through astrocyte processes (Fig. $3 A, B$ ), suggest that VEGF synthesized by astrocytes could participate in the recruitment of neural progenitors to perivascular niches for neuronal differentiation. It has already 

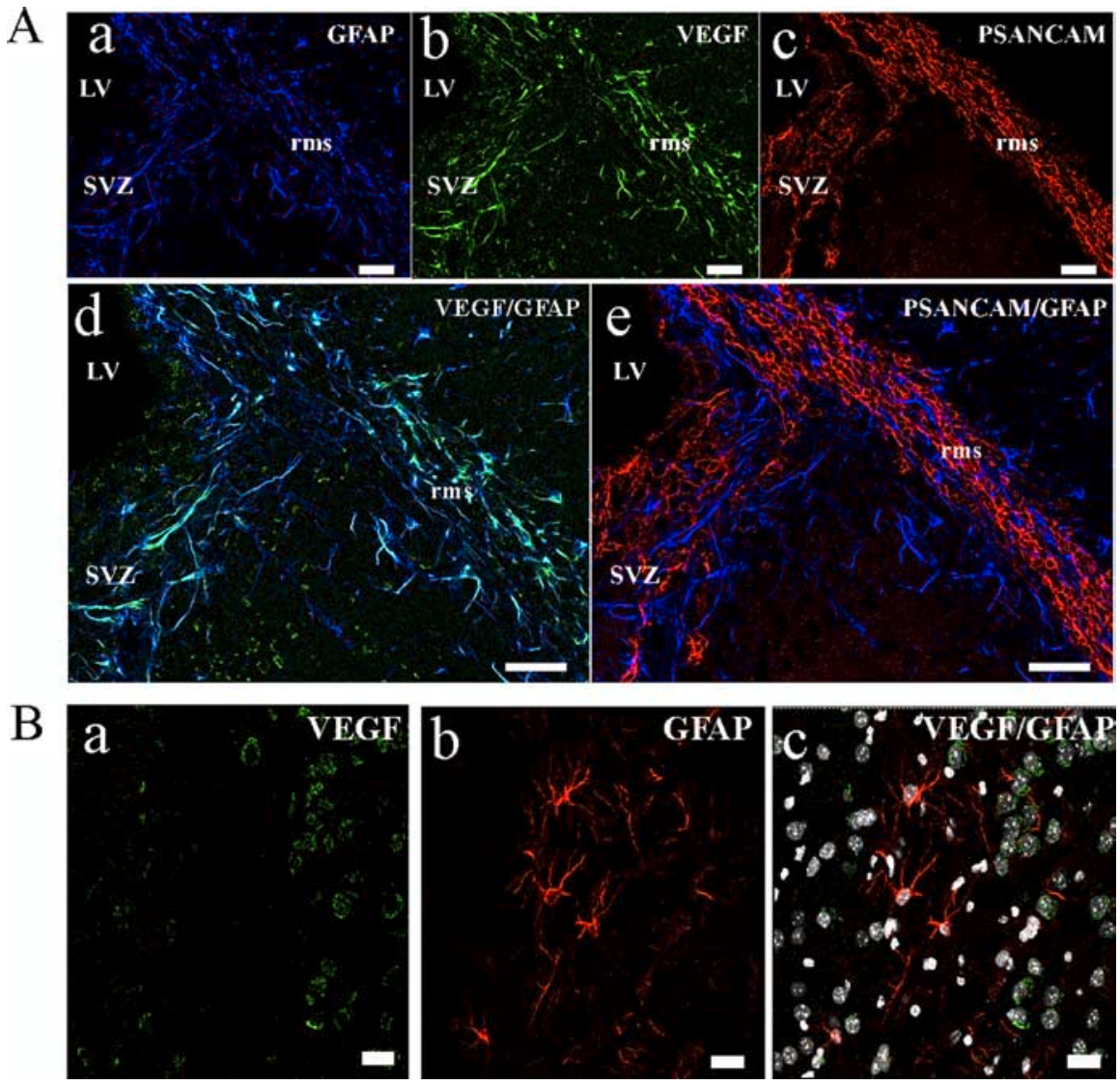

Figure 8. Astrocytes of the germinative SVZ and the RMS express VEGF. $\boldsymbol{A}$, Immunostaining on sagittal adult mouse brain sections with anti-GFAP ( $\boldsymbol{a}, \boldsymbol{d}, \boldsymbol{e}$; blue), anti-VEGF ( $\boldsymbol{b}, \boldsymbol{d}$; green), and anti-PSA-NCAM (c and e; red) antibodies demonstrate a colocalization of VEGF with GFAP + astrocytes in the aSVZ and RMS. LV, Lateral ventricle. $\boldsymbol{B}$, Double immunostaining of adult mouse striatum with anti-VEGF $(\boldsymbol{a}, \boldsymbol{c})$ and anti-GFAP $(\boldsymbol{b}, \boldsymbol{c})$ antibodies. Slice was counterstained with Hoechst for DNA (c). VEGF immunoreactivity is not detected in astrocytes of the striatal parenchyma. Scale bars, $50 \mu \mathrm{m}$.

been established that neurogenesis occurs in foci closely associated with blood vessels (Palmer et al., 2000), that astrocytes are important for neurogenesis (Song et al., 2002), and that endothelial cells secrete factors that stimulate neural progenitor survival and differentiation (Louissaint et al., 2002; Shen et al., 2004). We propose that IQGAP1 could contribute to VEGF signaling that triggers neural progenitor migration to neurogenic niches for neuronal differentiation. In support of this hypothesis, we observed a delay in differentiation of neural progenitors into neuronal precursors in Iqgap1-null mice (Fig. 4) that can be explained by an altered migration to neurogenic niches.

In vitro, migratory signal triggered in neural progenitor by VEGF correlates with the formation of stable complex between IQGAP1 and the Rho-family GTPases Cdc42/Rac1 and with Lis 1 (Fig. 7), three major partners of IQGAP1 in cell motility signal transduction (Fukata et al., 2002; Mataraza et al., 2003; YamaokaTojo et al., 2004; Kholmanskikh et al., 2006). It has been demonstrated previously that IQGAP1 is phosphorylated on Tyr and Ser residues in endothelial and epithelial cells by membrane associated kinases such as receptor-associated Tyr kinase and protein kinase $\mathrm{C}$, and this could influence IQGAP1 activities (YamaokaTojo et al., 2004; Li et al., 2005). So, we have investigated whether phosphorylation of IQGAP1 by VEGF receptor-associated kinases could contribute to enhance interaction of IQGAP1 with Rho-family GTPases in neural progenitors (supplemental Fig. $2 C$, available at www.jneurosci.org as supplemental material). In neurosphere cells, IQGAP1 did not incorporate phosphate on
Ser/Thr or Tyr residues in resting cells or after VEGF stimulation. It is therefore likely that other signaling pathways triggered after VEGF stimulation of neural progenitors are responsible for stimulating IQGAP1 interaction with Rho-family GTPase and Lis1. Calcium signaling is a strong candidate. Previous studies reported that calcium influx promotes IQGAP1 delocalization from the cytosol to the plasma membrane (Mbele et al., 2002) and that $\mathrm{Ca}^{2+}$ influx regulates the interaction of IQGAP1 with Rho-family GTPase and Lis1 (Kholmanskikh et al., 2006). We also have found that VEGF stimulation of neural progenitors does promote transient $\mathrm{Ca}^{2+}$ increase in wild-type neurosphere cells (supplemental Fig. $3 A$, available at www.jneurosci.org as supplemental material). These observations corroborate a recent study showing that VEGF-R2 stimulation triggers $\mathrm{Ca}^{2+}$ increase in endothelial cells (Dawson et al., 2006). The possible contribution of $\mathrm{Ca}^{2+}$ signaling in VEGFmediated migratory response is also supported by the observation that chelation of intracellular calcium by acetoxy methyl ester of bis-(2-amino-5-phenoxy)ethane$N, N, N^{\prime}, N^{\prime}$-tetraacetic acid inhibited neurosphere cell migration in response to VEGF stimulation (supplemental Fig. 3B, available at www.jneurosci.org as supplemental material). Deciphering the role of $\mathrm{Ca}^{2+}$ signaling in IQGAP1-mediated migration in neural progenitors requires further investigations.

In the mouse RMS, IQGAP1 is also expressed by migrating neuronal precursors (PSA-NCAM+ type A cells). The expression of IQGAP1 in neural precursors is consistent with a recent study showing that IQGAP1 is expressed by cerebellar immature neurons grown in vitro (Kholmanskikh et al., 2006). Comparison between wild-type and Iggap1-null mice revealed no significant differences in the timing of migration of neuronal precursors and postmitotic neuroblast to reach the granular layers of the $\mathrm{OB}$ (supplemental Fig. 4, available at www.jneurosci.org as supplemental material). This suggests that mice probably develop compensatory mechanisms. Other molecules could compensate for IQGAP1 in neuroblast migration in vivo. A very recent study identified a novel member of the IQGAP family, IQGAP3, which is highly expressed in adult brain (Wang et al., 2007). IQGAP3 exhibits a high degree of homology with IQGAP1 in the conserved domains; it is also an effector of Rac1/Cdc42 and an actinbinding protein (Wang et al., 2007). Interestingly, IQGAP3 is important for neurite outgrowth downstream of Rac1/Cdc42 in NGF-stimulated PC12 cells or hippocampal neurons, but IQGAP1 is dispensable (Wang et al., 2007). Thus, IQGAP1 and IQGAP3 could be involved in common or in different regulatory pathways, but with partially redundant functions. It is therefore possible that IQGAP3 compensates for IQGAP1 in neuroblast migration along the RMS and within the OB but not in VEGFinduced migration in uncommitted neural progenitors. It is noteworthy that in contrast to neural progenitors (PSANCAM - ), differentiated neuroblasts (PSA-NCAM+) do not ex- 
press VEGF receptors and do not respond to VEGF migration signal (Zhang et al., 2003). Consequently, IQGAP isoforms can be differentially mobilized according to migratory signals.

Finally, the proposed function of IQGAP1 in the regulation neural progenitor motility can be extended to the amplifying tumorigenic cells in human glioblastoma multiforme (GBM). In a rat model of GBM and in human GBM, but not in oligodendrogliomas, IQGAP1 has been identified as a new molecular marker of niches of amplifying tumor cells that share common antigenic characteristics and architectural organization with neural progenitors (Balenci et al., 2006). It is likely that the IQGAP1 signaling pathway might also play an essential role in the control of the amplifying tumor cell migration in these highly invasive tumors.

\section{References}

Acker T, Beck H, Plate KH (2001) Cell type specific expression of vascular endothelial growth factor and angiopoietin-1 and -2 suggests an important role of astrocytes in cerebellar vascularization. Mech Dev 108:45-57.

Alvarez-Buylla A, Garcia-Verdugo JM (2002) Neurogenesis in adult subventricular zone. J Neurosci 22:629-634.

Balenci L, Clarke ID, Dirks PB, Assard N, Ducray F, Jouvet A, Belin MF, Honnorat J, Baudier J (2006) IQGAP1 protein specifies amplifying cancer cells in glioblastoma multiforme. Cancer Res 66:9074-9082.

Briggs MW, Sacks DB (2003) IQGAP proteins are integral components of cytoskeletal regulation. EMBO Rep 4:571-574.

Brown MD, Sacks DB (2006) IQGAP1 in cellular signaling: bridging the GAP. Trends Cell Biol 16:242-249.

Cao L, Jiao X, Zuzga DS, Liu Y, Fong DM, Young D, During MJ (2004) VEGF links hippocampal activity with neurogenesis, learning and memory. Nat Genet 36:827-835.

Dawson NS, Zawieja DC, Wu MH, Granger HJ (2006) Signaling pathways mediating VEGF165-induced calcium transients and membrane depolarization in human endothelial cells. FASEB J 20:991-993.

Doetsch F, Garcia-Verdugo JM, Alvarez-Buylla A (1997) Cellular composition and three-dimensional organization of the subventricular germinal zone in the adult mammalian brain. J Neurosci 17:5046-5061.

Fukata M, Watanabe T, Noritake J, Nakagawa M, Yamaga M, Kuroda S, Matsuura Y, Iwamatsu A, Perez F, Kaibuchi K (2002) Rac1 and Cdc42 capture microtubules through IQGAP1 and CLIP-170. Cell 109:873-885.

Gritti A, Bonfanti L, Doetsch F, Caille I, Alvarez-Buylla A, Lim DA, Galli R, Verdugo JM, Herrera DG, Vescovi AL (2002) Multipotent neural stem cells reside into the rostral extension and olfactory bulb of adult rodents. J Neurosci 22:437-445.

Hashimoto T, Zhang XM, Chen BY, Yang XJ (2006) VEGF activates divergent intracellular signaling components to regulate retinal progenitor cell proliferation and neuronal differentiation. Development 133:2201-2210.

Jin K, Zhu Y, Sun Y, Mao XO, Xie L, Greenberg DA (2002) Vascular endothelial growth factor (VEGF) stimulates neurogenesis in vitro and in vivo. Proc Natl Acad Sci USA 99:11946-11950.

Jin K, Sun Y, Xie L, Peel A, Mao XO, Batteur S, Greenberg DA (2003) Directed migration of neuronal precursors into the ischemic cerebral cortex and striatum. Mol Cell Neurosci 24:171-189.

Kholmanskikh SS, Koeller HB, Wynshaw-Boris A, Gomez T, Letourneau PC, Ross ME (2006) Calcium-dependent interaction of Lis1 with IQGAP1 and Cdc42 promotes neuronal motility. Nat Neurosci 9:50-57.
Lee MY, Ju WK, Cha JH, Son BC, Chun MH, Kang JK, Park CK (1999) Expression of vascular endothelial growth factor mRNA following transient forebrain ischemia in rats. Neurosci Lett 265:107-110.

Li S, Wang Q, Chakladar A, Bronson RT, Bernards A (2000) Gastric hyperplasia in mice lacking the putative Cdc42 effector IQGAP1. Mol Cell Biol 20:697-701.

Li Z, McNulty DE, Marler KJ, Lim L, Hall C, Annan RS, Sacks DB (2005) IQGAP1 promotes neurite outgrowth in a phosphorylation-dependent manner. J Biol Chem 280:13871-13878.

Lois C, Alvarez-Buylla A (1994) Long-distance neuronal migration in the adult mammalian brain. Science 264:1145-1148.

Louissaint Jr A, Rao S, Leventhal C, Goldman SA (2002) Coordinated interaction of neurogenesis and angiogenesis in the adult songbird brain. Neuron 34:945-960.

Lui WY, Mruk DD, Cheng CY (2005) Interactions among IQGAP1, Cdc42, and the cadherin/catenin protein complex regulate Sertoli-germ cell adherens junction dynamics in the testis. J Cell Physiol 202:49-66.

Mataraza JM, Briggs MW, Li Z, Entwistle A, Ridley AJ, Sacks DB (2003) IQGAP1 promotes cell motility and invasion. J Biol Chem 278:41237-41245.

Mbele GO, Deloulme JC, Gentil BJ, Delphin C, Ferro M, Garin J, Takahashi M, Baudier J (2002) The zinc- and calcium-binding S100B interacts and co-localizes with IQGAP1 during dynamic rearrangement of cell membranes. J Biol Chem 277:49998-50007.

Noritake J, Watanabe T, Sato K, Wang S, Kaibuchi K (2005) IQGAP1: a key regulator of adhesion and migration. J Cell Sci 118:2085-2092.

Palmer TD, Willhoite AR, Gage FH (2000) Vascular niche for adult hippocampal neurogenesis. J Comp Neurol 425:479-494.

Rosenstein JM, Mani N, Khaibullina A, Krum JM (2003) Neurotrophic effects of vascular endothelial growth factor on organotypic cortical explants and primary cortical neurons. J Neurosci 23:11036-11044.

Schanzer A, Wachs FP, Wilhelm D, Acker T, Cooper-Kuhn C, Beck H, Winkler J, Aigner L, Plate KH, Kuhn HG (2004) Direct stimulation of adult neural stem cells in vitro and neurogenesis in vivo by vascular endothelial growth factor. Brain Pathol 14:237-248.

Shen Q, Goderie SK, Jin L, Karanth N, Sun Y, Abramova N, Vincent P, Pumiglia K, Temple S (2004) Endothelial cells stimulate self-renewal and expand neurogenesis of neural stem cells. Science 304:1338-1340.

Song H, Stevens CF, Gage FH (2002) Astroglia induce neurogenesis from adult neural stem cells. Nature 417:39-44.

Strawn LM, McMahon G, App H, Schreck R, Kuchler WR, Longhi MP, Hui TH, Tang C, Levitzki A, Gazit A, Chen I, Keri G, Orfi L, Risau W, Flamme I, Ullrich A, Hirth KP, Shawver LK (1996) Flk-1 as a target for tumor growth inhibition. Cancer Res 56:3540-3545.

Temple S, Alvarez-Buylla A (1999) Stem cells in the adult mammalian central nervous system. Curr Opin Neurobiol 9:135-141.

Wang S, Watanabe T, Noritake J, Fukata M, Yoshimura T, Itoh N, Harada T, Nakagawa M, Matsuura Y, Arimura N, Kaibuchi K (2007) IQGAP3, a novel effector of Rac1 and Cdc42, regulates neurite outgrowth. J Cell Sci 120:567-577.

Yamaoka-Tojo M, Ushio-Fukai M, Hilenski L, Dikalov SI, Chen YE, Tojo T, Fukai T, Fujimoto M, Patrushev NA, Wang N, Kontos CD, Bloom GS, Alexander RW (2004) IQGAP1, a novel vascular endothelial growth factor receptor binding protein, is involved in reactive oxygen species-dependent endothelial migration and proliferation. Circ Res 95:276-283.

Zhang H, Vutskits L, Pepper MS, Kiss JZ (2003) VEGF is a chemoattractant for FGF-2-stimulated neural progenitors. J Cell Biol 163:1375-1384. 